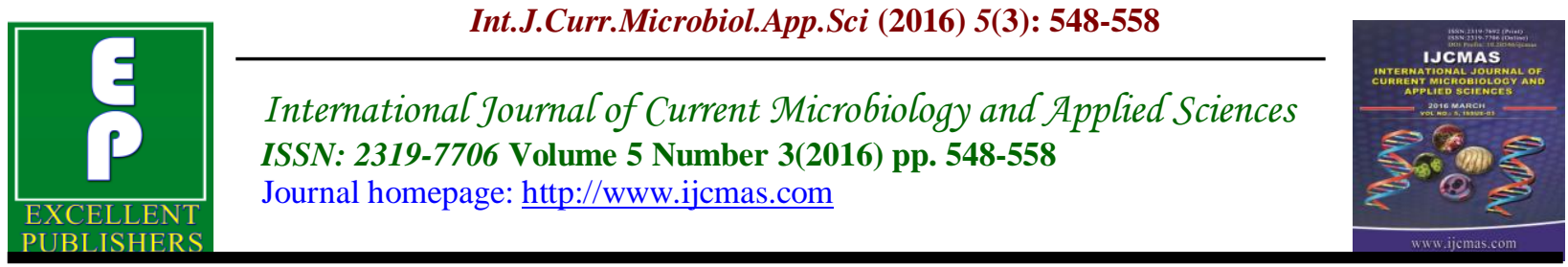

Review Article

http://dx.doi.org/10.20546/ijcmas.2016.503.064

\title{
Production of Metal Nanoparticles from Biological Resources
}

\author{
Pankaj K. Tyagi* \\ Department of Biotechnology, Meerut Institute of Engineering and Technology, \\ Meerut U.P. India \\ *Corresponding author
}

\begin{tabular}{ll}
\hline & A B S T R A C T \\
\cline { 2 - 3 } Keywords & $\begin{array}{l}\text { There are various methods to synthesize AgNPs. Many methods are based on the } \\
\text { reduction of } \mathrm{Ag}^{+} \text {ions in a water solution. These methods use a reducing agent for } \\
\text { the reduction of } \mathrm{Ag}^{+} \text {ions in solution. A variety of chemical and physical } \\
\text { Metallic }\end{array}$ \\
$\begin{array}{l}\text { Nanoparticles, } \\
\text { Bacteria, Yeast, } \\
\text { Virus, and Plant }\end{array}$ & $\begin{array}{l}\text { methods are fraught with many problems including use of toxic solvents, } \\
\text { generation of hazardous by-products, and high energy consumption. Accordingly, } \\
\text { Material. }\end{array}$ \\
$\begin{array}{l}\text { there is an essential need to develop environmentally benign procedures for } \\
\text { synthesis of metallic nanoparticles. A promising approach to achieve this objective } \\
\text { is to exploit the array of biological resources in nature. Indeed, over the past several } \\
\text { years, plants, algae, fungi, bacteria, and viruses have been used for production of } \\
\text { low-cost, energy-efficient, and nontoxic metallic nanoparticles. In addition, the } \\
\text { current interest in nanomaterials is focused on the controllable properties of size } \\
\text { and shape because the optical, electronic, magnetic, and catalytic properties of } \\
\text { metal nanoparticles strongly depend on their sizes and shapes. Controllability in } \\
\text { biological methods is far easier to achieve than with other methods. Therefore, the } \\
\text { use of microorganisms in the synthesis of nanoparticles emerges as an eco-friendly } \\
\text { and exciting approach. }\end{array}$ \\
\hline $\begin{array}{l}\text { Accepted: } \\
\text { Available Online: } \\
\text { 10, March 2016 }\end{array}$
\end{tabular}

\section{Introduction}

The term "Nanotechnology" has been coined by Norio Taniguchi, a researcher at the University of Tokyo, Japan (Tanja et al., 1999). This slowly expanded to various fields. Even when various scientists reported the remediation of various heavy metals by microorganisms, the remediated nanosized zero valent metal crystal remained unnoticed (Mullen et al., 1989). But, when the significances of the nanoparticles were discovered, their applications also increased.
When it comes to silver nanoparticles, they are used as antimicrobial agents in most of the public places such as elevators and railway stations in China. Besides, they are used as antimicrobial agents in surgically implanted catheters in order to reduce the infections caused during surgery and are proposed to possess antifungal, antiinflammatory, antiangiogenic and antipermeability activities (Kalishwaralal et al., 2009, Gurunathan et al., 2009, Sheikpranbabu et al., 20098). Silver was 
known only as a metal till recently and it is only when the nano era came into existence that people started to believe that silver could even be produced at the nanoscale. As previously mentioned, nanoparticles remained unnoticed even when many organisms were used for remediation of various metals. The competent organisms have been used to remove various reactive metal salts from the environment. Both the Gram positive and Gram negative metals have been used for the biosorption of metals such as silver, cadmium and copper. Various organisms have been tested for their efficiency to adsorb these metal ions and these metal ions remained as a colloidal aggregate mostly on the cell surface, occasionally on the cytoplasm. The size of the nanoparticles played no significant role during those times. These capable organisms were in turn termed as the "competent organisms" which could bind large amounts of metal ions (Beveridge et al., 1976, Doyle et al., 1980, Beveridge and Fyfe 1985). Cell walls of Gram positive bacteria such as Bacillus subtilis were found to bind with large quantities of metals than the Gram negative bacteria such as Escherichia coli (Beveridge and Fyfe 1985). The synthesis methods in the early 1980s described the reduction of metal ion as a two step procedure; in first step very small particles were synthesized, which were then enlarged to several nanometers. The difference remained in the use of the reducing agent for the synthesis where in the former step a stronger reducing agent was used, and in latter step a weaker reducing agent was used (Sintubin et al., 2009). The biosynthesis of nanoparticles as an emerging highlight of the intersection of nanotechnology and biotechnology has received increasing attention due to a growing need to develop environmentally benign technologies in material synthesis (Deepak et al., 2008). The biological synthesis of nanoparticles germinated from the experiments on biosorption of metals with Gram negative and Gram positive bacteria. The synthesized molecules were not identified as nanoparticles but as aggregates (Mullen et al., 1989).

\section{Fundamental Concept of Nanobiotechnology}

Nanotechnology is the engineering of functional systems at the molecular scale. This covers both current work and concepts that are more advanced. In its original sense, nanotechnology refers to the projected ability to construct items from the bottom up, using techniques and tools being developed today to make complete, high performance products. One nanometer is one billionth part, or $10^{-9}$ of a meter. By comparison, typical carbon-carbon bond lengths, or the spacing between carboncarbon atoms in a molecule are in the range $0.12-0.15 \mathrm{~nm}$, and a DNA doublehelix has a diameter around $2 \mathrm{~nm}$. On the other hand, the smallest cellular life-forms, the bacteria of the genus Mycoplasma, are around $200 \mathrm{~nm}$ in length. By convention, nanotechnology is taken as the scale range 1 to $100 \mathrm{~nm}$ following the definition used by the National Nanotechnology Initiative in the US. Nanoscale materials and devices can be fabricated using either "bottom-up" or "top-down" fabrication approaches. In bottom-up methods, nanomaterials or structures are fabricated from buildup of atoms or molecules in a controlled manner that is regulated by thermodynamic means such as self-assembly (Ferrari et al., 2005). Alternatively, advances in micro technologies can be used to fabricate nanoscale structures and devices. These techniques, which are collectively referred to top-down nanofabrication technologies, include photolithography, nanomolding, dippen lithography and nanofluidics (Peppas et 
al., 2004, Sahoo et al., 2003). It is perhaps because of the breadth of different approaches in the synthesis and fabrication of nano-molecules and nano-devices that chemical engineers are playing a key role in advancing the field of nanotechnology. On one hand, chemical engineers possess the skills to understand molecular events through modeling and simulation as well as thermodynamic and kinetic calculations; while on the other hand, they have the ability to understand systems, device miniaturatizaion and fluidics associated with top-down fabrication strategies.

\section{Background History of Metal Nanoparticals}

The concept of nanotechnology though considered to be a modern science has its history dating to as back as the $9^{\text {th }}$ century. Nanoparticles of gold and silver were used by the artisans of Mesopotamia to generate a glittering effect to pots. The first scientific description of the properties of nanoparticles was provided in 1857 by Michael Faraday in his famous paper "Experimental relations of gold and other metals to light" (Faraday et al., 1857). In 1959, Richard Feynman gave a talk describing molecular machines built with atomic precision. This was considered the first talk on nanotechnology. This was entitled "There's plenty of space at the bottom". The 1950's and the 1960's saw the world turning its focus towards the use of nanoparticles in the field of drug delivery. One of the pioneers in this field was professor Peter Paul Speiser, his research group at first investigated polyacrylic beads for oral administration, then focused on microcapsules and in the late 1960s developed the first nanoparticles for drug delivery purposes and for vaccines. The nano revolution conceptually started in the early 1980's with the first paper on nanotechnology being published in 1981 by
K. Eric Drexler of space systems laboratory, Massachuetts Institute of Technology. This was entitled "An approach to the development of general capabilities for molecular manipulation".

\section{Types and uses of Metal Nanoparticals}

The two types of nanoparticals are investigated to yet i.e. organic and inorganic nanoparticles. Organic nanoparticles include carbon nanoparticles such as fuller family (C-60 family) or fullerenes while inorganic nanoparticles includes magnetic nanoparticles/noble metal nanoparticles such as gold and silver and semiconductor nanoparticles such as titanium dioxide and zinc oxide. Now a days research or researcher shows their keen interest in inorganic nanoparticles as they provide superior material properties with functional versatility. Due to their size features and advantages over available chemical imaging drugs agents and drugs, inorganic nanoparticles have been examined as potential tools for medical imaging as well as for treating diseases. Inorganic nanomaterials have been widely used for cellular delivery due to their versatile features like wide availability, rich functionality, good biocompatibility, capability of targeted drug delivery and controlled release of drugs (Xu et al., 2006). For example mesoporous silica when combined with molecular machines prove to be excellent imaging and drug releasing systems. Gold nanoparticles have been used extensively in imaging, as drug carriers and in thermo therapy of biological targets (Cheon and Horace , 2009). Inorganic nanoparticles both metallic and semiconductors exhibit intrinsic optical properties which may enhance the transparency of polymer- particle composites. For such reasons, inorganic nanoparticles have found special interest in 
studies devoted to optical properties in composites. For instance, size dependant colour of gold nanoparticles has been used to colour glass for centuries (Caseri et al., 2009).

\section{Biological Pathways for Metal Nanoparticle Synthesis}

\section{Biosynthesis of Metal Nanoparticles from Microorganism}

The use of microbial cells for the synthesis of nanosized materials has emerged as a novel approach for the synthesis of metal nanoparticles. The biosynthesis of nanomaterials via microorganism is recent in which, the interactions between microorganisms and metals have been well documented and the ability of microorganisms to extract or accumulate metals is employed in commercial biotechnological processes such as bioleaching and bioremediation (Gericke and Pinches, 2006). Bacteria are known to produce inorganic materials either intra cellular or extra cellular. Microorganisms are considered as a potential biofactories for the synthesis of nanoparticles like gold, silver, cadmium, sulphide and zinc. Some well known examples of bacteria synthesizing inorganic materials include magnetotactic bacteria (synthesizing magnetic nanoparticles) and S layer bacteria which produce gypsum and calcium carbonate layers (Shankar et al., 2004). As mentioned above, living organisms such as bacteria, fungi and plants have huge potential for the production of metal nanoparticles. The use of microorganisms in the synthesis of nanoparticles emerges as an eco-friendly and exciting approach (Salata et al., 2004, He et al., 2007). On the other hand, researchers have turned to biological synthesis because of the good control over size distribution of nanoparticles (Ahmad et al., 2003, Bansal et al., 2005).

\section{By using Bacteria (Prokaryotic Micro Machine)}

The first synthesis of $\mathrm{Ag}$ nanoparticles by bacteria was reported in 2000. Joerger et al. used $P$. stutzeri AG259 to synthesize Ag nanoparticles with size less than $200 \mathrm{~nm}$. Bacteria were grown on Lennox L (LB) agar substrate, containing $50 \mathrm{mmol} \mathrm{L}^{-1} \mathrm{AgNO} 3$, at $30^{\circ} \mathrm{C}$ for $48 \mathrm{~h}$ in the dark (Joerger et al., 2000). In 2008, biosynthesis of silver nanocrystals by Bacillus licheniformis was studied. Aqueous silver ions were reduced to silver nanoparticles when added to the biomass of $B$. licheniformis. This was indicated by the change in color from whitish-yellow to brown. The probable mechanism for the formation of silver nanoparticles involves the enzyme nitrate reductase (Kalimuthu et al., 2008). In 2008, silver nanoparticles in the range of $50 \mathrm{~nm}$ were synthesized by the supernatant of $B$. licheniformis when silver nitrate was added to it. The synthesized silver nanoparticles were highly stable. Also, the time required for reaction completion was 24 hour (Kalishwaralal et al., 2008). Biosynthesis of silver nanoparticles by using microorganisms was rather slow. However, finding microorganisms to synthesize $\mathrm{Ag}$ nanoparticles is an important aspect. Shahverdi et al. reported on the rapid synthesis of metallic nanoparticles of silver using the reduction of aqueous $\mathrm{Ag}+$ ion using the culture supernatants of Klebsiella pneumonia, Escherichia coli, (Lee et al., 1996, Shehata et al., 1971) and Enterobacter cloacae (Enterobacteriacae). The synthetic process was quite fast and silver nanoparticles were formed within 5 min of the silver ion coming into contact with the cell filtrate (Shahverdi et al., 2007). However, the culture supernatants of different bacteria from Enterobacteriacae are potential candidates for the rapid synthesis of silver nanoparticles. In 2009, investigated 
was the effect of different visible-light irradiation on the formation of silver nanoparticles from silver nitrate using the culture supernatant of Klebsiella pneumonia. In addition, the study experimentally investigated the liquid mixing process effect on silver nanoparticle synthesis by visible light irradiation. That study successfully synthesized evenly dispersed silver nanoparticles of uniform size and shape in the range of 1-6 $\mathrm{nm}$ and average size of 3 nm (Mokhtari et al., 2009). Another report focused on the synthesis of metallic bionanoparticles of silver using a reduction of aqueous $\mathrm{Ag}+$ ion with the culture supernatants of Staphylococcus aureus. The observation indicated that the reduction of the $\mathrm{Ag}+$ ions took place extracellularly. Also, the reaction between this supernatant and $\mathrm{Ag}+$ ions was carried out in bright conditions for 5 minutes (Nanda et al., 2009).

\section{By using Actinomycetes (Prokaryotic Micro Machine)}

Metal nanoparticles produced either intracellular or extracellular is of interest to scientists. But it was not very high and was far inferior to that obtained by conventional methods. Most of the actinomycetes especially the thermophilic actinomycetes, Thermomonospora spp. was exposed to sliver nitrate for getting AgNPs and chloroauric acids for AuNPs reduced extracellular (Konishi et al., 2004). These micro-organisms have developed numerous special adaptations to survive in such extreme habitats which include new mechanism of enzyme transduction, regulating metabolism, maintaining the structure and function of the membrane. Actinomycetes are micro organisms that can share important characteristics of fungi and bacteria (Sastry et al., 2003). Even though the actinomycetes have close relation with the mycobacterium and coryneforms, they were originally designated with 'ray fungi' (Strahlenpilze). These actinomycetes are able to produced secondary metabolites. The nanoparticles were also found to be nontoxic to the cells which continued to multiply even after the formation of the nanoparticles.

\section{By using Algae (Unicellular Green Algae)}

Similar to yeast, there are few, if any, reports of algae being used as a "biofactories" for synthesis of metallic nanoparticles. Recently, Singaravelu et al adopted a systematic approach to study the synthesis of metallic nanoparticles by Sargassum wightii (Singaravelu et al., 2007) This is the first report in which a marine alga has been used to synthesize highly stable extracellular gold nanoparticles in a relatively short time period compared with that of other biological procedures. Indeed, $95 \%$ of the bioreduction of chloroauric ions occurred within 12 hours at stirring condition (Singaravelu et al., 2007)

\section{By using Yeast (Eukaryotic Micro Machine)}

Few, if any, reports exist about yeastmediated synthesis of metallic nanoparticles. In an individual report, silver nanoparticles in the size range of $2-5 \mathrm{~nm}$ were synthesized extracellularly by a silver-tolerant yeast strain MKY3, when challenged with $1 \mathrm{mmol}$ $\mathrm{L}^{-1}$ soluble silver in the log phase of growth (Liqin et al., 2010).

\section{By using Fungi (Eukaryotic Micro Machine)}

The use of fungi in the synthesis of nanoparticles is a relatively recent addition to the list of microorganisms. The use of fungi is potentially exciting since they 
secrete large amounts of enzymes and are simpler to deal with in the laboratory ( $\mathrm{He} e t$ al., 2008, Hong et al., 2009). Fungi have been widely used for the biosynthesis of nanoparticles and the mechanistic aspects governing the nanoparticle formation have also been documented for a few of them. In addition to monodispersity, nanoparticles with well defined dimensions can be obtained using fungi. Compared to bacteria, fungi could be used as a source for the production of large amount of nanoparticles. This is due to the fact that fungi secrete more amounts of proteins which directly translate to higher productivity of nanoparticle formation (Mohanpuria et al., 2008). Extracellular secretion of the microorganisms offers the advantage of obtaining large quantities in a relatively pure state, free from other cellular proteins associated with the organism with relatively simpler downstream processing. Mycelia free spent medium of the fungus, Cladosporium cladosporioides was used to synthesise silver nanoparticles extracellularly. It was hypothesized that proteins, polysaccharides and organic acids released by the fungus were able to differentiate different crystal shapes and were able to direct their growth into extended spherical crystals (Balaji et al., 2009). Fusarium oxysporum has been reported to synthesize silver nanoparticles extracellularly. Studies indicate that a nitrate reductase was responsible for the reduction of silver ions and the corresponding formation of silver nanoparticles. However Fusarium moniliformae did not produce nanoparticles either intracellularly or extracellularly even though they had intracellular and extracellular reductases in the same fashion as Fusarium oxysporum. This indicates that probably the reductases in F.moniliformae were necessary for the reduction of $\mathrm{Fe}$ (III) to $\mathrm{Fe}$ (II) and not for $\mathrm{Ag}$ (I) to Ag (0) (Duran et al., 2005)

\section{Biosynthesis of Metal Nanoparticles from Plant Extracts}

Whereas microorganisms such as bacteria, actinomycetes, yeasts, and fungi continue to be researched and investigated in synthesis of metallic nanoparticles, the use of parts of whole plants for similar nanoparticle biosynthesis methodologies is an exciting possibility that is relatively unexplored and underexploited (Pankaj et al., 2012). Synthesis of AgNPs by reduction of aqueous $\mathrm{Ag}^{+}$ions by the extract of onion, garlic, papaya and apple and their toxicity has been reported (Pankaj et al., 2016). In comparison with the earlier studies on the synthesis of AgNPs using bacteria or fungi, the reduction of the $\mathrm{Ag}^{+}$ions by this plant extract occurs fairly rapidly. Indeed, the time required for completion of the reaction (ie, complete reduction of the metal ions) using bacteria and fungi ranged from 24 to 124 hours; in contrast, more than $90 \%$ of the reaction using extract of geranium leaves is complete within 9 hours. Of note, to compete with chemical methods for synthesis, the time required for complete reduction should be reduced further. Nevertheless, the reduction of the metal ions occurs readily in solution and results in a high density of extremely stable crystalline AgNPs in the size range 16 to $40 \mathrm{~nm}$ with an average size of approximately $27 \mathrm{~nm}$. Using FTIR analysis, Shankar et al postulated that terpenoids present in the plant extract contribute to reduction of $\mathrm{Ag}^{+}$ions (Shankar et al., 2004). In a separate study, lemongrass (Cymbopogon flexuosus) plant extract was used for synthesis of triangular gold nanoprisms (Shankar et al., 2004). A singlestep, room-temperature reduction of aqueous $\mathrm{AuCl}^{4-}$ ions was performed to obtain the triangular gold nanoprisms. Assemblies of spherical nanoparticles that seemed to be "liquid-like" formed the nanotriangles. This fluidity occurred due to nanoparticle surface 
complexation of aldehydes or ketones present in the lemongrass plant. In a mechanistic study, Armendariz et al reported that the size of gold nanoparticle produced by Avena sativa (Oat) biomass was highly dependent on the $\mathrm{pH}$ outside (Armendariz et al., 2004). At pH 2, larger nanoparticles (25 to $85 \mathrm{~nm}$ ) were formed albeit in small quantities. Interestingly, at $\mathrm{pH} 3$ and 4, smaller nanoparticles were formed in larger quantities. Armendariz et al put forth a speculative scenario to provide an explanation for these intriguing observations. The authors reasoned that at low $\mathrm{pH}(\mathrm{ie}, \mathrm{pH}=2)$, the process of aggregation of gold nanoparticles to form larger nanoparticles is favored over the nucleation to form new nanoparticles. In contrast, at $\mathrm{pH} 3$ and 4, more functional groups are available for gold binding; thus a higher number of $\mathrm{Au}$ (III) complexes bind to the biomass at the same time. The coalescence of the silver nanoparticles could represent a self-protective mechanism against possible toxic effects of excess silver inside the living plant (Thakkar et al., 2010). The advantage of using plants for the synthesis of nanoparticles is that they are easily available, safe to handle and possess a broad variability of metabolites that may aid in reduction. A number of plants are being currently investigated for their role in the synthesis of nanoparticles. Gold nanoparticles with a size range of 2- $20 \mathrm{~nm}$ have been synthesized using the live alfa alfa plants (Torresday et al., 2002). The results of an investigation showed that alfalfa roots are capable of absorbing silver as $\mathrm{Ag}^{0}$ from the agar medium and then transferring it to the shoot of the plant in the same oxidation state. Gardea et al. used a natural source (Alfalfa Sprouts) for the synthesis of silver nanoparticles. The particles are usually found in specific areas in the plants. These areas are possibly related to the internal anatomy of alfalfa stems. The plants absorb Ag atoms through specific channels, and consequently, the Ag nucleates or coalesces as particles inside these channels. However, nanoparticles also were found outside the channels. This observation was either due to a collapse in the plant structure, allowing the silver nanoparticles to move out of these original areas, or possibly due to silver diffusing and nucleating nanoparticles in different places. Nanoparticles of silver, nickel, cobalt, zinc and copper have also been synthesized inside the live plants of Brassica juncea (Indian mustard), Medicago sativa (Alfa alfa) and Heliantus annus (Sunflower). Certain plants are known to accumulate higher concentrations of metals compared to others and such plants are termed as hyperaccumulators. Of the plants investigated, Brassica juncea had better metal accumulating ability and later assimilating it as nanoparticles (Bali et al., 2006). Recently gold nanoparticles have been synthesized using the extracts of Magnolia kobus and Diopyros kaki leaf extracts. The effect of temperature on nanoparticle formation was investigated and it was reported that polydisperse particles with a size range of 5-300nm was obtained at lower temperature while a higher temperature supported the formation of smaller and spherical particles (Song et al., 2009).

\section{Biosynthesis of Metal Nanoparticles from Viruses}

Biological approaches to nanocrystal synthesis have been extended to intact biological particles. Viral scaffolds can template the nucleation and assembly of inorganic materials. Indeed, cowpea chlorotic mottle virus and cowpea mosaic virus have been used as nucleation cages for the mineralization of inorganic materials (Douglas et al., 2002, Douglas et al., 1993). 
Furthermore, tobacco mosaic virus has been shown to direct successfully the mineralization of lead sulfide $(\mathrm{PbS})$ and $\mathrm{CdS}$ crystalline nanowires (Shankar et al., 2003). Taking the idea one step further, peptides capable of nucleating nanocrystal growth have been identified from combinatorial screens and displayed on the surface of M13 bacteriophage

In conclusion, Nanotechnology and nanofabrication has opened its doors to a world of metal nanopartical synthesis with easy preparation protocols, less toxicity and a wide range of applications according to their size and shape. Metal nanoparticles of desired size and shape have been obtained successfully using living organisms- simple unicellular organisms to highly complex eukaryotes. A critical need in the field of nanotechnology is the development of a reliable and ecofriendly process for synthesis of metallic nanoparticles. To accomplish this, the use of natural sources like biological systems becomes essential. The synthesis of inorganic materials by biological systems is characterized by processes that occur close to ambient temperature and pressures and also at neutral $\mathrm{pH}$. Of the various biological systems, bacteria are relatively easy to manipulate genetically, whereas fungi have an advantage of easy handling during downstream processing and large-scale production. Irrespective of the biological system used, in order to exploit the system to its maximum potential, it is essential to understand the biochemical and molecular mechanism of nanoparticle synthesis. However, the biological systems have been relatively unexplored, and there are many opportunities for budding nanobiotechnologists to use the biological systems for metallic nanoparticle synthesis. Importantly, for commercialization purposes, it would be advantageous to have a nonpathogenic biological system that produces the metallic nanoparticles.

\section{Acknowledgement}

Authors are thankful to Chairman, Director General, Director, of Meerut Institute of Engineering Technology for their continuous encouragement and problem solving assistance.

\section{References}

Ahmad A, Senapati S, Khan MI, Kumar R, Sastri M: Extracellular biosynthesis of monodisperse gold nanoparticles by novel extremophilic actinomycetes, Thermomonospora sp. Langmuir. 2003, 19: 3550-3553.

Armendariz V, Herrera I, Peralta-Videa JR, Jose-Yacaman M, Troiani H, Santiago P, Gardea-Torresdey JL. (2004) Size controlled gold nanoparticle formation by Avena sativa biomass: use of plants in nanobiotechnology. J Nanoparticle Res. 6:377-82.

Balaji, D.S.; Basavaraja, S.; Deshpande, R.; Mahesh, D.B.; Prabhakar, B.K. \& Venkataraman, A. (2009). Extracellular biosynthesis of functionalized silver nanoparticles by strains of Cladosporium cladosporioides fungus. Colloids and surfaces B: biointerfaces 68.; 88- 92

Bali, R.; Razak, N.; Lumb, A. \& Harris, A.T. (2006). The synthesis of metal nanoparticles inside live plants. IEEE Xplore. doi 10.1109/ICONN.2006. 340592

Bansal V, Rautaray D, Bharde A, Ahire K, Sanyal A, et al. Fungus-mediated biosynthesis of silica and titania particles. J Mater Chem. 2005; 15:2583-2589.

Beveridge TJ, Fyfe WS (1985) Metal fixation by bacterial cell walls. Can J 
Earth Sci 22:1893-1898

Beveridge TJ, Murray RGE (1976) Uptake and retention of metals by cell walls of Bacillus subtilis. J Bacteriol 127:1502-1518

Caseri, W. (2009). Inorganic nanoparticles as optically effective additives for polymers. Chemical Engineering Communications 196(5).; 549- 572.

Cheon, J. \& Horace, G. (2009). Inorganic nanoparticles for biological sensing, imaging and therapeutics. J. Mater. Chem. 19.; 6249- 6250

Douglas T, Strable E, Willits D, Aitouchen A, Libera M, Young M. Protein engineering of a viral cage for constrained nanomaterials synthesis. Adv Mater 2002;14:415-8.

Douglas T, Young M. Host-guest encapsulation of materials by assembled virus protein cages. Nature 1993;393:152-5.

Doyle RJ, Matthews TH, Streips UN (1980) Chemical basis for selectivity of metal ions by the Bacillus subtilis cell wall. J Bacteriol 143:471-480

Duran, N.; Marcato, P.D.; Alves, O.L.; De Souza; G.I.H. \& Esposito, E. (2005). Mechanistic aspects of biosynthesis of silver nanoparticles by several Fusarium oxysporum strains. Nanobiotechnology 3.; 8- 14.

Faraday, M. (1857). Experimental relations of gold (and other metals) to light. Phil. Trans. Roy. Soc. London 147.; 145-181

Ferrari, M., "Cancer Nanotechnology: Opportunities and Challenges," Nat Rev Cancer, 5 (3), pp. 161-171 (2005)

Gericke, M. \& Pinches, A. (2006). Microbial production of gold nanoparticles. Gold bulletin., 39(1); $22-28$

Gurunathan S, Kalishwaralal K, Vaidyanathan R, Venkataraman D, Pandian SRK, Muniyandi J, Hariharan
N, Eom SH (2009b) Biosynthesis, purification and characterization of silver nanoparticles using Escherichia coli. Colloids Surf B 74(1):328-335

He S, Guo Z, Zhang Y, Zhang S, Wang J, $\mathrm{Gu} \mathrm{N}$ : Biosynthesis of gold nanoparticles using the bacteriaRhodopseudomonas capsulate. Mater Lett. 2007, 61: 3984-3987. 10.1016/j.matlet.2007.01.018.

HE, S., ZHANG, Y., GUO, Z., GU, N., BIOLOGICAL SYNTHESIS OF GOLD NANOWIRES USING EXTRACT OF RHODOPSEUDOMONAS CAPSULATA. BIOTECHNOL PROG. 2008 MAR-APR;24(2):47680. DOI: $10.1021 / \mathrm{BP} 0703174$

Hong L., Li Q., Lin H. \& Li Y. Synthesis of flower-like silver nanoarchitectures at room temperature. Mater. Res. Bull. 44, 1201-1204 (2009)

Joerger, R., Klaus, T., Granqvist, C. G., Biologically produced silver-carbon composite materials for optically functional thin-film coatings. Adv. Mater. 12, (6) (2000) 407-409.

Deepak, K., V, Ramkumarpandian S, Nellaiah H, Sangiliyandi G (2008) Extracellular biosynthesis of silver nanoparticles by the culture supernatant of Bacillus licheniformis. Mater Lett 62:4411-3

Kalimuthu K, Babu RS, Venkataraman D, Bilal M, Gurunathan S. Biosynthesis of silver nanocrystals by Bacillus licheniformis. Colloids and Surfaces B. 2008;65(1):150-153.

Kalishwaralal K, Banumathi E, Pandian SBRK, Deepak V, Muniyandi J, Eom SH (2009) Silver nanoparticles inhibit VEGF induced cell proliferation and migration in bovine retinal endothelial cells. Colloids Surf B 73:51-7

$\begin{array}{cccc}\text { Kalishwaralal } & \text { K, } & \text { Deepak } & \text { V, } \\ \text { Ramkumarpandian } & S, \text { Nellaiah } & H,\end{array}$


Sangiliyandi G. Extracellular biosynthesis of silver nanoparticles by the culture supernatant of Bacillus licheniformis. Materials

Letters. 2008;62(29):4411-4413.

Konishi Y, Ohno K, Saitoh N, Nomura T, Nagamine S (2004). Microbial synthesis of gold nanoparticles by metal reducing bacterium. TransMater Res Soc Jpn; 29:2341-2343. 34.

Lee, S. Y. 1996. High cell-density culture of Escherichia coli. trends.

Biotechnol. 14:98-105.

Liqin Lin, Wenta Wang, Jiale Huang, Qingbiao Li, Daohua Sun, Xin Yang, Huixuan Wang, Ning He, Yuanpeng Wang, (2010). Nature factory of silver nanowires: Plant-mediated synthesis using broth of Cassia fistula leaf, Chemical Engineering Journal 162 852-858

Mohanpuria, P.; Rana, K.N. \& Yadav, S.K (2008). Biosynthesis of nanoparticles:technological concepts and future applications. Journal of Nanoparticle Research 10.; 507- 517.

Mokhtari N., Daneshpajouh S., Seyedbagheri S., Atashdehghan R., Abdi K, Sarkar S., Minaian S., Shaverdi H.R., Shaverdi A.R, Biological synthesis of very small silver nanoparticles by culture supernatant of Klebsiella pneumonia: The effects of visible-light irradiation and the liquid mixing process. Mater. Res.Bull. 2009; 44: 1415-1421..

Mullen MD, Wolf DC, Ferris FG, Beveridge TJ, Flemming CA, Bailey GW (1989) Bacterial sorption of heavy metals. Appl Environ Microbiol 55:31433149

Nanda A., Saravanan M., Biosynthesis of silver nanoparticles from Staphylococcus aureus and its antimicrobial activity against MRSA and MRSE. Nanomedicine. 2009; 5:
452-456.

Pankaj, K.T., Mansi, M., Nida, K., Shruti, T., Sandeep, S. 2016

Pankaj, K.T., Shruti, Vikas Sarsar and Anami Ahuja 2012. Synthesis of metal nanoparticles: A Biological prospective for analysis. International Journal Of Pharmaceutical Innovations. 2 (4): 48-60

Peppas, N. A., "Intelligent Therapeutics: Biomimetic Systems and Nanotechnology in Drug Delivery," Advanced Drug Delivery Reviews, 56 (11), pp. 1529-1531 (2004)

Sahoo, S. K., and V. Labhasetwar, "Nanotech Approaches to Drug Delivery and Imaging," Drug Discov Today, 8 (24), pp. 1112-1120 (2003).

Salata OV: Application of nanoparticles in biology and medicine. $\mathrm{J}$ Nanobiotechnol. 2004, 2: 3-9. 10.1186/1477-3155-2-3.

Sastry M, Ahmad A, Khan I, Kumar R (2003). Biosynthesis of metal nanoparticles using fungi and actinomycete. Curr Sci; 85(2):162-170

Shahverdi A.R., Minaeian S., Shahverdi H.R., Jamalifar H., Nohi A.A., Rapid synthesis of silver nanoparticles using culture supernatants of Enterobacteriaceae: a novel biological approach. Process Biochem. 2007; 42: 919-923.

Shankar S, Ahmad A, Sastry M. Geranium leaf assisted biosynthesis of silver nanoparticles, Biotechnol. Prog, 19, 2003, 1627-1631.

Shankar S, Rai A, Ankamwar B, Singh A, Ahmad A, Sastry M. Biological synthesis of triangular gold nanoprisms. Nat Mater 2004;3: 482-8.

Shankar, S.S.; Rai, A.; Ahmad, A. \& Sastry, M. (2004). Rapid synthesis of $\mathrm{Au}, \mathrm{Ag}$ and bimetallic $\mathrm{Au}$ core- $\mathrm{Ag}$ shell nanoparticles using neem (Azadirachta indica) leaf broth. Journal of colloid 
and interface science. 275.; 496-502.

Shehata, T. E., Marr, A. G., Effect of nutrient concentration on the growth of Escherichia coli.J. bacteriol. 107 (1) (1971) 210-206.

Sheikpranbabu S, Kalishwaralal K, Venkataraman D, Eom SH, Park J, Gurunathan S (2009) Silver nanoparticles inhibit VEGF-and IL-1binduced vascular permeability via Src dependent pathway in porcine retinal endothelial cells. J Nanobiotechnol 7:8

Singaravelu G, Arockiamary J, Ganesh K, Govindaraju K. A novel extracellular synthesis of monodisperse gold nanoparticles using marine alga, Sargassum wightii Greville. Colloids Surf B Biointerfaces 2007; 57:97-101.

Sintubin L, De Windt W, Dick J, Mast J, Ha DV, Verstraete W, Boon N (2009) Lactic acid bacteria as reducing and capping agent for the fast and efficient production of silver nanoparticles. Appl Microbiol Biotechnol 84(4):741-
749

Song, Y.J.; Jang, H-K.; Kim, S.B. (2009). Biological synthesis of gold nanopaticles using Magnolia kobus and Diopyros kaki leaf extract, Process Biochemistry, 44, 1133-1138

Tanja K, Ralph J, Eva O, Claes-G€oran G (1999) Silver-based crystalline nanoparticles, microbially fabricated. Proc Natl Acad Sci 96:13611-13614

Thakkar, T. N., Mhatre, S. S., Parikh, R. Y., Nanomed. 6 (2010) 257.

Torresday, J.L.G.; Parsons, J.G.; Gomez, E.; Videa, J.P.; Troiani, H.E.; Santiago, P. \& Yacaman, M.J. (2002). Formation and growth of $\mathrm{Au}$ nanoparticles inside live alfa alfa plants. Nanoletters 2(4); 397- 401

Xu, Z.P.; Zeng, Q.H.; Lu, G.Q. \& Yu, A.B. (2006). Inorganic nanoparticles as carriers for efficient cellular delivery. Chemical Engineering Science 61.; 1027- 1040.

\section{How to cite this article:}

Pankaj K. Tyagi. 2016. Production of Metal Nanoparticles from Biological Resources Int.J.Curr.Microbiol.App.Sci. 5(3): 548-558. doi: http://dx.doi.org/10.20546/ijcmas.2016.503.064 